\title{
Prostatic Study of Extract of Sida Acuta on Wistar Rats
}

\section{Kebe E Obeten ${ }^{1 *}$, Victor A Fischer ${ }^{2}$, Gabriel Udo-Affah ${ }^{2}$, Etah E Nkanu ${ }^{3}$}

${ }^{1}$ Department of Anatomy and Forensic Science, Cross River University of Technology, Okuku, Nigeria

${ }^{2}$ Department of Anatomy, University of Calabar, Calabar, Nigeria

${ }^{3}$ Department of physiology, Cross River University of Technology, Okuku, Nigeria

*Corresponding Author: Kebe E Obeten, Department of Anatomy and Forensic Science, Cross River University of Technology, Okuku, Nigeria.

Received: July 02, 2019; Published: July 11, 2019

DOI: $10.31080 /$ ASPS.2019.03.0337

\section{Abstract}

This study was carried out to evaluate the effects of ethanolic leaf extract of Sida acuta on the prostrate of male Wistar rats. Twenty five rats weighing between 180 - $220 \mathrm{~g}$ were assigned to five groups (control, olive oil control, low dose, medium dose and high dose) with five animals each. Normal control fed only on rat chow, olive oil control group received $0.5 \mathrm{ml}$ of olive oil. The experimental groups, low dose, medium dose and high dose received $500 \mathrm{mg} / \mathrm{kg}$ body weight, $1000 \mathrm{mg} / \mathrm{kg}$ body weight, $1500 \mathrm{mg} / \mathrm{kg}$ body weight of the extract orally for 60 days respectively. The animals in the control groups and the experimental groups were weighed before and after the administrations of the ethanolic extracts of Sida acuta using sensitive balance. All animals were sacrificed at end of sixty days of administration using chloroform anesthesia. The prostate glands were dissected and sectioned for hematoxylin and eosin (H\&E) stains. Morphological result from the study revealed increased final body weight compared to the initial body weight. Histological observations of the prostate showed dose dependent distortion of the normal cytoarchitecture, as the high dose revealed prominent distortion. Hence the study suggests that consumption of Sida acuta at high dose may cause adverse effect on the protrate.

Keywords: Protrate; Sida acuta

\section{Introduction}

Utilization of plant medicine existed long before historical documentation by man. There are useful medicinal compounds in plants and spices used by humans to season food [1,2]. For many decades, treatment of human diseases has been dependent on the knowledge of herbal medicine [3], as such, these medicines have been used in many countries such as Nigeria, South Africa, and Bangladesh to proffer solution for many infertility problems plaguing the society [4-6]. Development of formulas and pharmacopoeias has been based on ethnomedicnal plant-use data resulting meaningfully to drug manufacturing [7].

Knowledge of modern medicine is derived from plants. The increase worldwide reliance in herbal plants indicates acknowledgment of the usefulness of these plants in health care [8]. Different generations through experimental procedures have provided useful information on the therapeutic benefits of plants of various origins. The increase access to information on tradition medicine as well as its proximity, less constraining and low price has countered the argumentative effects of chemical drugs and their high cost, as such leading to an increase drift by the public to the use of traditional medicine [9].

Herbs play a major role in the regulation of human ailments and this cannot be overemphasized. Obviously, plant kingdom contains unlimited source of active vital in the treatment of many headstrong diseases [10].

The purity, suitable extraction method, adverse effects and the dosage of toxicity of plants are core parameters needed to be known [11], poor knowledge of these parameters has led to various health related problems including infertility which commonly affects most couples world over [12]. Males account for about 30\% of infertility worldwide [13] and this is a thing of huge concern, but is neglected in Nigeria [14].

Contraceptives may be developed from many plant products, but so far only few plants (Kamboj, 1988), such as ethanol extract of Dioscorea esculanta [15] and Andrograpis paniculata [16] which impeded fertility in both sexes in animal models have been studied. 
There is little or no literature on the effects of Sida acuta ethanolic extract on male reproductive system. In Ugep urban of Yakurr Local Government Area, this herb is used in the treatment of venereal disease as well as fertility related problems. Thus this research is carried out to investigate the effect of Sida acuta on reproductive parameters and organs in the male Wistar rats.

\section{Materials and Method}

Extract preparation

Fresh Sida acuta leaves was harvested from farms in Ugep, Yakuur Local Government Area of Cross River State and taken to the herbarium unit of the University of Calabar, Calabar for proper identification and authentication. Debris were removed from the leaves by washing, air dried and grounded into powder, then stored in dry air tight containers.

Abdulrahman., et al. (2004) modified method was used for extraction. $200 \mathrm{~g}$ of grounded Sida acuta leaves were soaked in $1000 \mathrm{ml}$ absolute ethanol, labelled and properly covered for 72 hours, after which sterile filter paper (Watman No. 1) was used to filter extract. The filtrate was evaporated to dryness at $40 \mathrm{oC}$ in a vacuum using a rotator evaporator and stored at $50 \mathrm{oC}$ in a refrigerator until required for use. Approximate concentration of the extract was dissolved in $10 \mathrm{ml}$ of olive oil. Olive oil was used as a vehicle.

\section{Experimental animals}

The study made use of twenty five male Wistar rats (8-10 weeks old, weighing180 -220 g) which was obtained from the Department of Pharmacology, University of Calabar, Calabar. The rats were housed in wire-wooden cages under controlled light schedule (12-hours light and 12-hours dark cycle) and were fed standard rat chow and water ad libitum. The animals acclimatized for 2 weeks before the startof the administration.

\section{Experimental design}

The rats were divided into 5 groups of 5 rats each. Control group was fed with standard rat chow and water ad libitum without any administration of the extract. Olive oil control group received 0.5 $\mathrm{ml}$ of olive oil throughout the duration of the experiment. The low dose group received $500 \mathrm{mg} / \mathrm{kgBw}$, medium dose group received $1000 \mathrm{mg} / \mathrm{kgBw}$ while the high dose group received $1500 \mathrm{mg} / \mathrm{kgBw}$ of the extract by means of orogastric tube daily, for 60 days respectively.

\section{Termination of experiment}

At the end of treatments, animals were sacrificed through chloroform inhalation. blood was collected from the left ventricle of the heart and stored in heparinized bottles for biochemical studies and hormonal assay. Epididymis, prostate and testis were removed and fixed in Bouins fluid for 24 hours for routine histological study, histochemical and immunohistochemical studies.

\section{Result}

Morphological observations

There was statistically significant increase in the final weight of animals in all the groups compared to their initial weight. The weight of the control group significantly $(\mathrm{p}<0.001)$ increased compared to the initial weight, olive oil control group significantly $(\mathrm{p}<0.01)$ increased compared to their initial body weight. The low dose (500mg/kgBW) and high dose groups (1500mg/kgBW) were significantly increased $(\mathrm{p}<0.001)$ when compared to their initial body weight. Animals treated with medium dose of the extract showed significant $(p<0.01)$ increase in final body weight compared to their initial body weight.

There was no significant difference in the final weight of all the experimental groups when compared to the normal control, except for the high dose group which showed significant decrease $(p<0.01)$ compared to the normal control. The weight of the low dose group was significantly higher $(\mathrm{p}<0.001)$ compared to the olive oil group, there was no significant difference between the olive oil control and the medium dose groups, while there was significant decrease $(\mathrm{p}<0.05)$ in the high dose group compared to the olive oil control group. Comparing between groups that were treated with Sida acuta extract, there was no significant difference in the final weight of animals in the low and medium dose, while the high dose group showed significant reduction $(\mathrm{p}<0.001)$ compared to the low dose group, but no significant difference when compared to the medium dose group.

\section{Histological observation of prostate gland}

Histological study of the prostate gland in the control group using haematoxylin and eosin staining method showed normal histological features. Many glands were found within their surface epithelium surrounded by connective tissue and smooth muscle and many prostatic concretions. There was no pathology seen in the olive control group as the glands appear normal with prostatic concretions as in control group. 
Animals in the low dose group which received $500 \mathrm{mg} / \mathrm{kgBw}$ of Sida acuta ethanolic leaf extract, showed normal epithelium surrounded by connective tissue and smooth muscle. No pathology was observed. The prostate gland in the medium dose group that received $1000 \mathrm{mg} / \mathrm{kgBw}$ of the extract showed normal architecture. The epithelial cells appeared normal, with normal folds surrounded by connective tissue and smooth muscle. There was no pathology seen.

In the high dose group, animals that received $1500 \mathrm{mg} / \mathrm{kgBw}$ of ethanolic leaf extract of Sida acuta, there was hyperplasia of the basal cells and less prostatic concretions.

Initial and final body weights of animals in various experimental groups

\begin{tabular}{|l|c|c|}
\hline \multicolumn{1}{|c|}{ Groups } & $\begin{array}{c}\text { Initial } \\
\text { body weight } \mathbf{( g )}\end{array}$ & $\begin{array}{c}\text { Final body } \\
\text { weight } \mathbf{( g )}\end{array}$ \\
\hline Normal control & $113.60 \pm 3.88$ & $156.00 \pm 4.91^{\mathrm{c}}$ \\
\hline Olive oil control & $136.80 \pm 0.80$ & $145.20 \pm 1.85^{\mathrm{b}}$ \\
\hline Low dose & $113.20 \pm 1.46$ & $170.80 \pm 4.90^{\mathrm{c}}$ \\
\hline Medium dose & $124.60 \pm 1.72$ & $155.20 \pm 8.87^{\mathrm{b}}$ \\
\hline High dose & $106.40 \pm 0.98$ & $136.00 \pm 3.33^{\mathrm{c}}$ \\
\hline
\end{tabular}

Table a

Values are presented as Mean \pm SEM, $n=5$

$\mathrm{b}=$ Significantly different from initial weight at $\mathrm{p}<0.01$

$c=$ Significantly different from initial weight at $p<0.001$

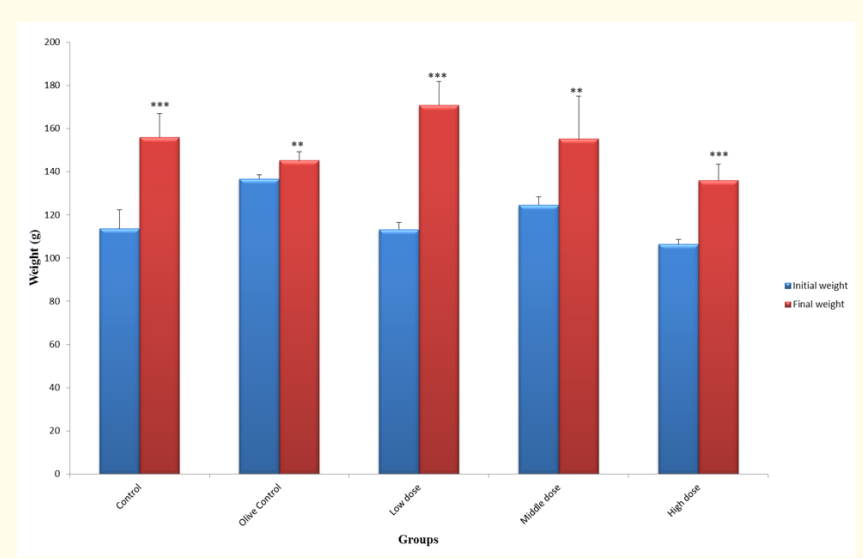

Figure 1: Initial and final mean body weight of different experimental groups.

Values are presented as Mean \pm SEM, $n=5$

** Significantly different from initial body weight at $\mathrm{p}<0.01$

*** Significantly different from initial body weight at $\mathrm{p}<0.001$

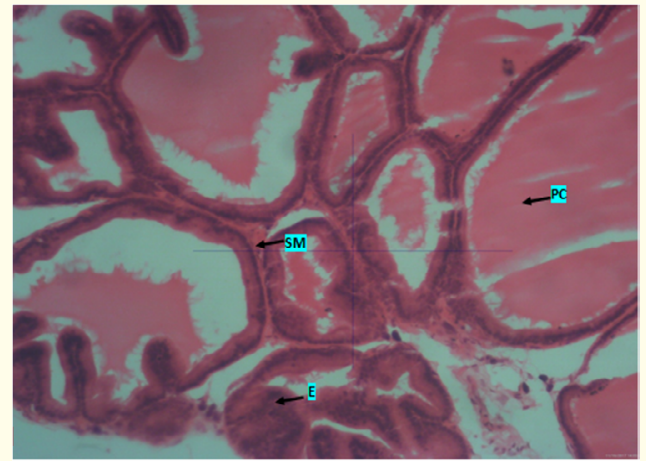

Plate 1: Photomicrograph of prostate of control group showing many glands with their surface epithelium (E) and many prostatic concretions (PC). Smooth muscle (SM) can be seen. No pathology seen. X400. H \& E.

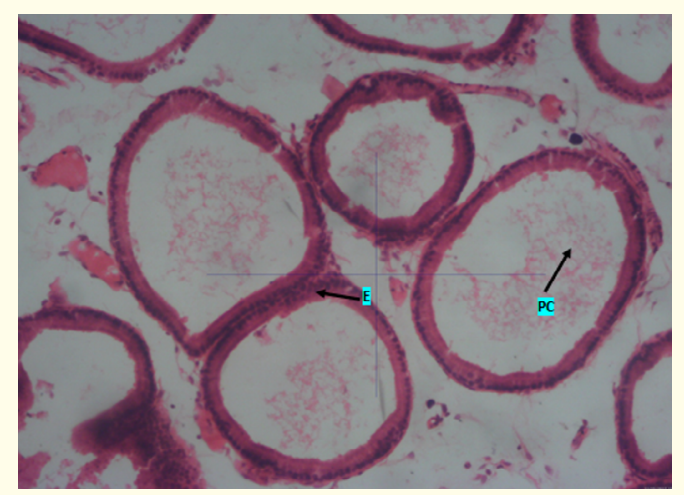

Plate 2: Photomicrograph of prostate of olive oil control group showing epithelial cells (E). The glands appear normal with prostatic concretions (PC). No pathology seen. X400. H \& E.

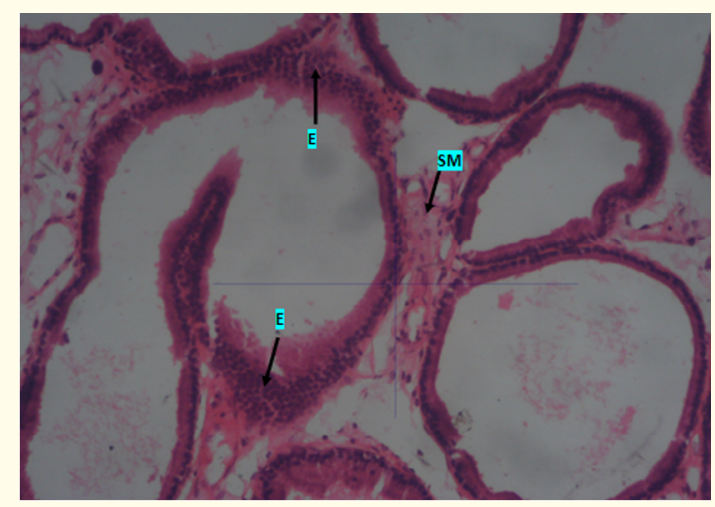

Plate 3: Photomicrograph of prostate of low dose group that received $500 \mathrm{mg} / \mathrm{kgBw}$ of Sida acuta ethanolic leaf extractshowing the epithelium (E). Smooth muscles (SM) was also seen. No pathology seen. X400. H \& E. 


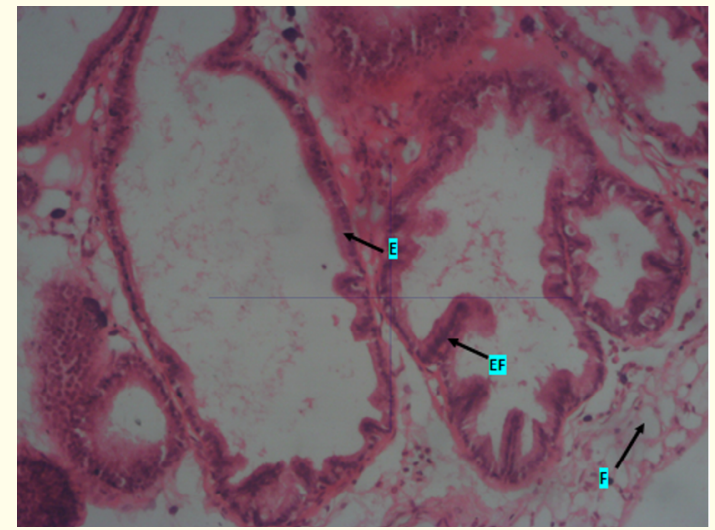

Plate 4: Photomicrograph of prostate of medium dose group that received $1000 \mathrm{mg} / \mathrm{kgBw}$ of Sida acuta ethanolic leaf extract showing a normal architecture. Epithelial cells (E) and epithelial folds (EF) appears normal. Few fat cells (F) are also seen. No pathology seen. X400. H \& E.

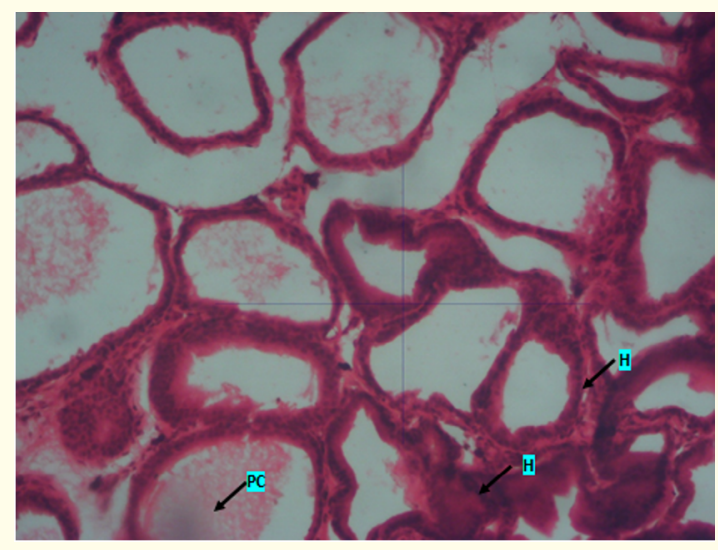

Plate 5: Photomicrograph of prostate of high dose group that received $1500 \mathrm{mg} / \mathrm{kgBw}$ of Sida acuta ethanolic leaf extract showing basal cell hyperplasia $(\mathrm{H})$ and less prostatic concretions (PC). X400. H \& E.

\section{Discussion}

The world today tends to drift away from synthetic drugs to natural plant products, thus increasing the dependence on plant extracts for treatment of all sorts of illnesses including infertility, with little or no undesirable side effects [17]. Due to this fact, plant extracts are used without caution and administered at outrageous doses over a long period of time without considering their adverse effects.
The prostate of the low and medium dose groups which received $500 \mathrm{mg} / \mathrm{kgBw}$ and $1000 \mathrm{mg} / \mathrm{kgBw}$ of the ethanolic extract showed normal concretions and glandular epithelium, ejaculatory ducts and prostatic fats were seen. This result confirms documented reports about the pharmacological benefits of Sida acuta as reported by Scalbert [18] and Halliwell [19] who stated that the presence of polyphenolic compounds of Sida acuta such as tannin and flavonoid which have strong antioxidant effect capable of blocking the toxic effect of free radicals by quenching their reactivity.

The administration of high dose of Sida acuta extract showed swollen glandular epithelium of prostatic glands with few stromal cells. This might be as a result of the administration of the extract at the high dose of over the duration of 60 days may have adverse effect on the integrity of the prostate gland. This result is not consistent with the work reported by Menaka., et al. [20] which states that Sida acuta plant ameliorate nephrotoxicity and renal dysfunction hence validates its ethnomedical use. This disagreement might be due to the differences in methodology, duration and dosages used.

\section{Conclusion}

From the results obtained in this study, it may be deduced that the administration of the extract of sida acuta leaf is dose dependent and showed adverse effect on almost all the parameters studied. Thus, intake of ethanoic leaf extract of sida acuta should be discouraged at high doses and long duration as it may be adverse to male fertility.

\section{Bibliography}

1. Tapsell LC., et al. "Health benefits of herbs and spices: the past, the present, the future". Medical Journal of Australia 185 (2006): S4-24.

2. Lai PK and Roy J. "Antimicrobial and chemopreventive properties of herbs and spices". Current Medical Chemistry 11 (2004): 1451-1460.

3. Iwalewa EO., et al. "Inflammation: the foundation of diseases and disorders. A review of phytomedicines of South African origin used to treat pain and inflammatory conditions". African Journal of Biotechnology 6 (2007): 2868-2885.

4. Kafaru E. "Immense help formative workshop". In Essential Pharmacology; 1st Ed. Elizabeth Kafaru Publishers: Lagos, Nigeria (1994). 
5. Mander M. "Medicinal plant marketing in Bushbukridge and Mpunalaga: A market survey and recommended strategies for sustaining the supply of plants in the region". Unpulbished report. Darudec and DWAF, South Africa (1998).

6. Apu AS., et al. "Anti-inflammatory activity of medicinal plants native to Bangladesh: A review". Journal of Applied Pharmaceutical Science 2 (2012): 07-10.

7. Graham JG., et al. "Plants used against cancer-an extension of the work of Jonathan Hartwell". Journal Ethnopharmacology 73 (2000): 347-377.

8. Ahmed M and Hussain F. "Chemical Composition and Biochemical Activity of Aloe Vera (Aloe Barbadensis Miller) Leaves". International Journal of Chemical and Biochemical Sciences 3.5 (2013): 29-33.

9. Agunbiade OS., et al. "Hypoglycaemic activity of Commelina africana and Ageratum conzyzoides in relation to their mineral composition". African Health Sciences 12 (2012): 198-203.

10. Palaksha MB and Ravishankar K. "Phytochemical Screening and Evaluation of in vitro Antibacterial and Antihelminthic Activities of Sida acuta Leaf Extracts". Journal of Chemical and Pharmaceutical Research 4 (2012): 4757-4761.

11. Murray A. "Dietary reference intake for antioxidant nutrients" 100 (1998): 637-640.

12. Leke R. "Reproductive health in Cameroon". Geneva, WHO. collaborating centre for Research in Human Reproduction (2008).

13. WHO. Traditional medicine and modern health care. Progress report by the Director General, Document A. 44 (10): 22 March 1991. World Health Organization, Geneva (1991).

14. Okonofua F., et al. "A case control study of risk factors for male infertility in Nigeria". Asian Journal Andrology 7 (2005): 351361.

15. Shajeela PS., et al. "Antifertility activity of ethanol extract of Dioscorea esculenta (L.) Schott on male albino rats". International Journal of Pharmacotechnology Research 3 (2011): 946-954

16. Akbarsha MA., et al. "Antifertility effect of Andrographis paniculata (Nees) in albino rats". Indian Journal Experimental Biology 28 (1990): 421-426.

17. Dada AA and Ajilore VO. "Use of ethanol extracts of Garcinia kola as fertility enhancer in female catfish Clarias gariepinus broodstock". International Journal of Fishery and Aquaculture 1 (2009): 005-010.
18. Scalbert A. "Antimicrobial properties of tannins". Phytochemistry 30 (1991): 3875-3883.

19. Halliwell B. "Free radicals, antioxidants, and human disease: curiosity, cause, or consequence". Lancet 344 (1994): 721-724.

20. Menaka C., et al. "Sida rhomboidea. Roxb Leaf Extract DownRegulates Expression of PPAR 22 and Leptin Genes in High Fat Diet Fed C57BL/6J Mice and Retards in Vitro 3T3L1 Pre-Adipocyte Differentiation". International Journal of Molecular Science 12 (2010): 4661-4677.

Volume 3 Issue 8 August 2019

(C) All rights are reserved by Kebe E Obeten., et al. 